\title{
Pattern of Esophageal Cancer in Sudan
}

\author{
Ali Adam Elhadi ${ }^{1}$, Hyder Osman Mirghani ${ }^{2}$, Yassin Ibrahim ${ }^{3}$, Ibrahim Abdullah Albalawi ${ }^{4}$ \\ ${ }^{1}$ Department of Internal Medicine, Medical College, Omdurman Islamic University, Omdurman, Sudan \\ ${ }^{2}$ Department of Internal Medicine, Faculty of Medicine, University of Tabuk, Tabuk, Kingdom of Saudi Arabia \\ ${ }^{3}$ Department of Community Medicine, Faculty of Medicine, University of Tabuk, Tabuk, Kingdom of Saudi Arabia \\ ${ }^{4}$ Department of Surgery, Faculty of Medicine, University of Tabuk, Tabuk, Kingdom of Saudi Arabia
}

\section{Email address:}

drbalawi@yahoo.com (I. A. Albalawi)

\section{To cite this article:}

Ali Adam Elhadi, Hyder Osman Mirghani, Yassin Ibrahim, Ibrahim Abdullah Albalawi. Pattern of Esophageal Cancer in Sudan. American Journal of Clinical and Experimental Medicine. Vol. 4, No. 6, 2016, pp. 166-169. doi: 10.11648/j.ajcem.20160406.12

Received: September 26, 2016; Accepted: October 5, 2016; Published: October 27, 2016

\begin{abstract}
Objectives: Carcinoma of the esophagus is the eights common cancer worldwide causing a lot of morbidity and mortality, defining the risk factors could aid prevention. In the current study, we aimed to explore the pattern of esophageal cancer in Sudan. Methods: Seventy-two patients referred for upper gastrointestinal endoscopy and diagnosed with esophageal cancer were studied in the endoscopy unit of Omdurman Teaching Hospital during the period November 2013 to April 2016. Endoscopy was doneand histopathology reported for all patients. Information collected were: demographic data, symptoms due to esophageal cancer, associated risk factors, type and site of the lesion. Results: Out of the seventy-two patients with esophageal carcinoma their ages ranged from 31-93 years with a mean of $62.57 \pm 15.1$ years, $40.1 \%$ were males. The commonest presentation was dysphagia (98.6\%) followed by loss of weight (93.1\%). The majority were adenocarcinomas [80.6\%], 91.6\% occur in middle and lower thirds of the esophagus. Reflux esophagitis was reported in $40.3 \%$, achalasia in $29.3 \%$, while hot drinks consumption was reported in $20.8 \%$. A significant statistical difference was evident between adenocarcinoma and squamous cell carcinoma regarding Achalasia presentation $\mathrm{P}$-value $<0.05$, no significant differences were found regarding age, sex, reflux esophagitis, hot and spicy food, and obesity P-value $>0.05$. Conclusion: Adenocarcinoma was commoner than squamous cell carcinoma, with the lower third of the esophagus more involved. A significant statistical difference was found between squamous cell adenocarcinoma and regarding achalasia., no significant differences were found regarding age, sex, reflux esophagitis, hot and spicy food, and obesity.
\end{abstract}

Keywords: Esophageal Cancer, Pattern, Sudan

\section{Introduction}

The incidence of the carcinoma of the esophagus varies considerably across the World with the highest rate observed in Central and East Africa and the lower incidence in South America and West Africa. The Squamous cell carcinoma is the commonest, although the frequency of the adenocarcinoma due to Barrette's esophagus is rising [1-3].

Worldwide near half million new cases were affected by esophageal cancer in the year 2012, and 400200 deaths occurred [4].

In Sudan gastrointestinal malignancies are the most common cancer with esophageal cancer constituted up to $25.3 \%$ in a study conducted in a Western province in Sudan $[5]$.
There is a tendency towards the increasing rate of adenocarcinoma with decreasing squamous cell carcinoma in different areas worldwide including the United States of America, Canada, Europe, Australia, and New Zealand attributed to change in various risk factors for each esophageal cancer [6, 7]. Healthier lifestyle (diets with more fruits and vegetables, and regular exercise) could decrease the incidence of both adenocarcinoma and squamous cell carcinoma while smoking and alcohol intake is more associated with squamous cell carcinoma $[6,7]$.

The incidence of esophageal cancer varies considerably across the globe depending on various genetic and environmental factors. The squamous cell carcinoma is more prevalent in the developing countries, while the adenocarcinoma is mainly a disease of the developed 
societies due to the increasing obesity and gastroesophageal reflux disease [8].

Achalasia is a chronic esophageal motility disorder that increases the rate of esophageal squamous cancer up to 33 folds, the dilated esophagus leads to bacterial overgrowth, decreased the clearance of acid and gastric contents leading to dysplasia and cancer [9]. Achalasia is believed to increase the incidence of both squamous cell and adenocarcinoma of the esophagussignificantly [10].

Sudan is a vast country with different social, ethnic, and environmental diversity, the changing face of esophageal cancer observed in the Western Countries may not apply to Sudan. Thus we conducted this research. In the current study, we aimed to assess the demographic, clinical characteristics, and the risk factors among Sudanese patients referred with the provisional diagnosis of esophageal carcinoma in Omdurman Teaching Hospital.

\section{Subjects and Methods}

A descriptive cross-sectional prospective Hospital-based study conducted among seventy patients with the tentative diagnosis of the carcinoma of the esophagus in Omdurman Teaching Hospital/ Sudan during the period November 2013 to April 2016.All patients were invited to sign a written informed consent then a structured questionnaire was filled to collect the following information; age, sex, residence, occupation, the presenting and associated symptoms, family history of carcinoma of the esophagus, spicy food, hot tea uptake, and reflux esophagitis. Endoscopy was done at the Endoscopy unit using 'a fiber optic gastro-duodenoscopy Olympus UK' after clinical evaluation and investigations. The standard techniques of instruments sterilization and patient positioning and follow up after the procedure were carried out. The areas examined were the esophagus, stomach, and upper part of the duodenum, any abnormality in these regions was reported. Mucosal biopsies were taken for histopathology. The study was approved by the ethical committee of Omdurman Teaching Hospital. The Statistical Package for Social Sciences (SPSS) was used for data analysis, the data were presents as percentages or mean \pm sd unless otherwise specified, the chi-square test was used to compare categorical data with a P-value of $<0.05$ considered significant.

\section{Results}

Out of the seventy-two of patients with the diagnosis of the carcinomas of the esophagus $40.1 \%$ were males, their ages ranged from 31-93 years with a mean of $62.57 \pm 15.1$. Dysphagia was the commonest presentation (98.6\%), followed by loss of weight $(93.1 \%)$, and anemia in (70.8\%).A cough was evident $61.1 \%$, chest pain in $58.3 \%$, while the hoarse voice was detected in $12.5 \%$. Four $(5.6 \%)$ were smokers and consuming spicy food, $20.8 \%$ of patients were consuming hot food, and $4.2 \%$ were obese. Reflux esophagitis was diagnosed in $40.3 \%$ of patients, while achalasia was diagnosed in $29.2 \%$. It is interesting to note that the majority $(91.6 \%)$ were in the middle and lower thirds of the esophagus $(20.8 \%$ and $70.8 \%)$ respectively. The majority were adenocarcinoma (80.6\%), and $19.4 \%$ were squamous cell carcinoma (Table No1).

In the present study, more than one-third were coming from Western Sudan (38.9\%), followed by Khartoum state (30.5\%), White Nile (18.1\%), Eastern Sudan (5.5\%), Northern Sudan (4.2\%), and Blue Nile (2.8\%) Table (2).

Table No (3): illustrated the site and histopathology of the carcinoma of the esophagus in which the commonest site was the lower third of the esophagus $(70.8 \%)$, followed by the middle third (20.8\%), and lower third (8.4\%). The majority were adenocarcinoma (80.6\%), while squamous cell carcinoma was evident in (19.4\%).

A significant statistical difference was found between adenocarcinoma and squamous cell carcinoma regarding achalasia ( $1.4 \%$ vs. $27.8 \%$ ) P-value 0.043 , no difference was concluded regarding spicy food $(1.4 \%$ vs. $4.2 \%)$ P-value 0.773. Table No (4) depicted the comparison between adenocarcinoma and squamous carcinoma regarding various risk factors.

Table 1. Characteristics of the study group.

\begin{tabular}{ll}
\hline Character & No\% \\
\hline Age & $31-93$ \\
Range & $62.57 \pm 15.1$ \\
Mean \pm sd & $30[41.7 \%]$ \\
Males & $71[98.6 \%]$ \\
Dysphagia & $67[93.1 \%]$ \\
Loss of weight & $42[58.3 \%]$ \\
Chest pain & $44[61.1 \%]$ \\
Cough & $9[12.5 \%]$ \\
Hoarse voice & $51[70.8 \%]$ \\
Anemia & $4[5.6 \%]$ \\
Smoking & $4[5.6 \%]$ \\
Spicy food & $15[20.8 \%]$ \\
Hot food & $3[4.2 \%]$ \\
Obesity & $29[40.3 \%]$ \\
Reflux & $21[29.2 \%]$ \\
Achalasia &
\end{tabular}

Table 2. Distribution of carcinoma of the esophagus in Sudan.

\begin{tabular}{l|l}
\hline Region & \% \\
\hline Western Sudan & 38.9 \\
White Nile & 18.1 \\
Khartoum & 30.5 \\
Eastern Sudan & 5.5 \\
Northern Sudan & 4.2 \\
Blue Nile & 2.8 \\
\hline
\end{tabular}

Table 3. Location and histopathology of esophageal cancer.

\begin{tabular}{ll}
\hline Character & $\%$ \\
\hline Upper third of esophagus & 8.4 \\
Middle third & 20.8 \\
Lower third & 70.8 \\
Adenocarcinoma & 80.6 \\
Squamous cell carcinoma & 19.4 \\
\hline
\end{tabular}


Table 4. Comparison between squamous cell and adenocarcinoma.

\begin{tabular}{llll}
\hline Character & $\begin{array}{l}\text { Squamous cell } \\
\text { carcinoma }\end{array}$ & Adenocarcinoma & P-value \\
\hline $\begin{array}{l}\text { Age } \\
\text { Sex } \\
\text { Males }\end{array}$ & $60 \pm 17.6$ & $63.1 \pm 14.5$ & 0.481 \\
Females & $4(5.5 \%)$ & $26(36.1 \%)$ & 0.268 \\
Smoking & $10(13.9 \%)$ & $32(44.4 \%)$ & \\
Spicy food & 0 & $4(5.5 \%)$ & 0.312 \\
Hot drinks & $1(1.4 \%)$ & $3(4.2 \%)$ & 0.773 \\
Obesity & $2(2.8 \%)$ & $13(18.1 \%)$ & 0.343 \\
Gastro-esophageal & 0 & $3(4.2 \%)$ & 0.385 \\
reflux & $4(5.5 \%)$ & $25(34.7 \%)$ & 0.32 \\
Achalasia & $1(1.4 \%)$ & $20(27.8 \%)$ & 0.043 \\
\hline
\end{tabular}

\section{Discussion}

In the present study, the mean age of patients with the carcinoma of the esophagus was 62.5 years with no differences between men and women similar to previous literature from Sudan in which the age of patients with esophageal carcinoma ranged from 50-70 with males and females equally affected [11].

The two primary environmental influences that increase squamous cell carcinoma is tobacco smoking and heavy alcohol consumption [12], in the present study no patient use, to consume ethanol and only $5.6 \%$ of patients were smoker this can explain in part the higher rate of adenocarcinoma in our data[80.6\%].

It is interesting to note that the majority of the esophageal cancer was adenocarcinoma, with the lower third involved in the majority of patients, this shift towards adenocarcinoma was observed in Western countries [13] due to the high prevalence of obesity and gastroesophageal reflux disease.

In the current data obesity was detected in only $4.2 \%$ of patients and can be explained by the advanced stage of the carcinoma at presentation, and the majority of patients had lost their weight.

Achalasia had been linked to the increasing incidence of esophageal cancer [both squamous and adenocarcinoma], in the present study achalasia was evident in $29.2 \%$ of patients and higher rates among adenocarcinoma, similarly Leeuwenburgh et al. [14] concluded the relationship of achalasia and esophageal cancer.

A recent meta-analysis found the association of hot food and drink with any esophageal cancer especially for squamous cell carcinoma [15], through injury to esophageal mucosa hot tea and coffee may predispose to esophageal cancer Islami et al. [16] In the current study, $20.8 \%$ of patients with esophageal cancer reported consumption of scalding tea.

There are different pathways in the carcinogenesis of adenocarcinoma, and squamous cell carcinoma: chronic irritation by smoking, alcohol consumption, and hot beverages in squamous and obesity and gastroesophageal reflux for adenocarcinoma [17].

In the present study reflux esophagitis was reported in $40.2 \%$ of esophageal cancer patients,). Gastro-esophageal reflux can lead to Barrett's esophagus which is a precancerous condition.

\section{In Conclusion}

Adenocarcinoma is commoner than squamous cell carcinoma in Sudan, with the lower third of the esophagus involvement in the majority of patients and near half of patients diagnosed with gastroesophageal reflux, further larger multi-center studies looking for other risk factors like dietary factors, cooking practices, and teeth loss are needed. The study had many limitations, the small size of the survey sample and the study was conducted at a single center so generalization cannot be insured.

\section{Acknowledgment}

We would like to acknowledge Alia Mohamed Mustafa, nurse at the Endoscopy Unit, Omdurman Teaching Hospital for data collection.

\section{References}

[1] Buas MF, Vaughan TL. Epidemiology and risk factors for gastroesophageal junction tumors: understanding the rising incidence of this disease. SeminRadiatOncol 2013; 23:3.

[2] Torre LA, Bray F, Siegel RL, et al. Global cancer statistics, 2012. CA Cancer J Clin 2015; 65:87.

[3] Gholipour C, Shalchi RA, Abbasi M. A histopathological study of esophageal cancer on the western side of the Caspian littoral from 1994 to 2003. Dis Esophagus 2008; 21:322.

[4] Pohl H, Sirovich B, Welch HG. Esophageal adenocarcinoma incidence: are we reaching the peak? Cancer Epidemiol Biomarkers Prev 2010; 19:1468.

[5] Doumi EA, Ahmed MA, Hamad AM. Pattern and incidence of cancer at El Obeid Hospital, Western Sudan. Sudan JMS 2009;4 (1): 43-46

[6] Ferlay J, Shin HR, Bray F, et al. GLOBOCAN 2008 v1.2, Cancer Incidence and Mortality Worldwide: IARC CancerBase No.10 [Internet]. Lyon, France: International Agency for Research on Cancer. Available from http://globocan.iarc.fr. Accessed June 18, 2013.

[7] Otterstatter MC, Brierley JD, De P, et al. Esophageal cancer in Canada: trends according to morphology and anatomical location. Can J Gastroenterol 2012; 26(10):723-27.

[8] Melhado RE, Alderson D, Tucker O. The Changing Face of Esophageal Cancer. Cancers 2010, 2, 1379-1404; doi:10.3390/cancers2031379

[9] MinamiH, Yamaguchi N, Matsushima K, Akazawa Y, Ohnita K, Takeshima F, Nakayama T, Hayashi T, Inoue H, Nakao K, IsomotoH. Improvement of endocytoscopic findings after per oral endoscopic myotomy (POEM) in esophageal achalasia; does POEM reduce the risk of developing esophageal carcinoma? Per oral endoscopic myotomy, endocytoscopy and carcinogenesis. BMC Gastroenterol. 2013; 13: 22 . 
[10] O'Neill OM, Johnston BT, Coleman HG. achalasia: a review of clinical diagnosis, epidemiology, treatment and outcomes. World J Gastroenterol. 2013 Sep 21; 19(35):5806-12. doi: 10.3748/wjg.v19.i35.5806.

[11] Boulos PB, Elmasri SH. Carcinoma of the esophagus in the Sudan. Trop Geogr Med. 1979 Jun; 29(2):150-4.

[12] Pandeya N, Olsen CM, Whiteman DC. Sex differences in the proportion of esophageal squamous cell carcinoma cases attributable to tobacco smoking and alcohol consumption. Cancer Epidemiol. 2013 Oct; 37(5): 579-84. doi: 10.1016/j.canep.2013.05.011. Epub 2013 Jul 2.

[13] Crane SJ, Richard Locke G, 3rd; Harmsen, W. S.; Diehl, N. N.; Zinsmeister, A. R.; Joseph Melton, L., 3rd; Romero, Y; Talley, N.J. The changing incidence of esophageal and gastric adenocarcinoma by anatomic sub-site. Aliment. Pharmacol. Ther. 2007; 25, 447-453.
[14] Leeuwenburgh I, Scholten P, Alderliesten J, Tilanus HW, Looman CW, Steijerberg EW, Kuipers EJ. Long-term esophageal cancer risk in patients with primary achalasia: a prospective study. Am J Gastroenterol. 2010 Oct; 105(10): 2144-9. doi: 10.1038/ajg.2010.263. Epub 2010 Jun 29.

[15] Andrici J, Eslick GD. Hot Food and Beverage Consumption and the Risk of Esophageal Cancer: A Meta-Analysis. Am J Prev Med. 2015 Dec; 49(6): 952-60. doi: 10.1016/j.amepre.2015.07.023.

[16] Islami F, Boffetta P, Ren JS, Pedoeim L, Khatib D, and Kamangar F. High-temperature beverages and Foods and Esophageal Cancer Risk -- A Systematic Review. Int J Cancer 2009. Aug 1; 125(3): 491-524.

[17] Chung CS, Lee YC, Wu MS. Prevention strategies for esophageal cancer: Perspectives of the East vs. West. Best Pract Res Clin Gastroenterol. 2015 Dec; 29(6): 869-83. doi: 10.1016/j.bpg.2015.09.010. Epub 2015 Oct 9. 